\title{
MATERIALIDADES ESPECTRALES: \\ RESISTENCIAS SENSIBLES A LA \\ DESAPARICIÓN FORZADA EN COLOMBIA ${ }^{1}$
}

\author{
Juan Ángel Agudelo Hernándezia) \\ Juan Nicolás Cardona Santofimio $o^{(b)}$ \\ Andrea Carolina Bello Tocancipáa
}

SPECTRAL MATERIALITIES: SENSITIVE RESISTANCES TO

ENFORCED DISAPPEARANCE IN COLOMBIA

MATERIALIDADES ESPECTRAIS: RESISTÊNCIAS SENSÍVEIS

AO DESAPARECIMENTO FORÇADO NA COLÔMBIA

Fecha de recepción: 21 de octubre del 2019

Fecha de aprobación: 01 de mayo del 2020

Disponible en línea: 29 de mayo del 2020

Sugerencia de citación:

Agudelo Hernández, J. A., Cardona Santofimio, J. N. y Bello Tocancipá, A. C. (2020). Materialidades espectrales: resistencias sensibles a la desaparición forzada en Colombia. Razón Crítica, 9, 103-130, doi: $10.21789 / 25007807.1609$

1 Este artículo es el resultado de dos investigaciones que se desarrollaron dentro del marco de la línea de investigación "Subjetividad, violencia y guerra" del Departamento de Psicología de la Universidad de los Andes. Una de ellas es el proyecto de investigación: "La habitabilidad del fantasma", financiada por la Facultad de Ciencias Sociales, y la segunda es la investigación de grado realizada por Andrea Carolina Bello, titulada "Cuando las palabras faltan, las manos hablan: construcciones de sentido en torno a las prácticas textiles en el conflicto armado colombiano".

(a) Juan Ángel Agudelo Hernández

Psicólogo y Magister en Psicología, Universidad de los Andes, Colombia

ja.agudelo11@uniandes.edu.co

https://orcid.org/0000-0002-9484-8525

(b) Juan Nicolás Cardona Santofimio

Psicólogo y Filósofo, Universidad de los Andes, Colombia

jn.cardona10@uniandes.edu.co

https://orcid.org/0000-0002-2531-639X

(c) Andrea Carolina Bello Tocancipá

Psicóloga, Universidad de los Andes, Colombia

ac.bello10@uniandes.edu.co

https://orcid.org/0000-0002-5696-8067 


\section{R E S U M E N}

En Colombia, la desaparición ha inscrito una violencia capaz de atacar no solo la vida, sino la existencia. Instaurando una lógica de terror fantástico, el lugar de las víctimas se desploma hacia un vacío de sentido que quiebra lo sensible y lo decible. No obstante, un acercamiento fenomenológico-hermenéutico a la experiencia de once familiares de desaparecidos en Colombia pone en duda el deseo totalizador de la violencia y revela que la introducción del no-lugar no suspende la relación con los ausentes. Más bien, nuestros resultados sugieren que el desaparecido puede resonar, manifestarse en sueños o hacerse tela en el acto de tejer. Es en estos espacios de aparición donde se articula una militancia en contra de la ausencia.

PALABRAS CLAVE: Desaparición forzada, sonido, prácticas textiles, sueños, memoria. 


\section{A B S T R A C T}

Enforced disappearance in Colombia has recorded a type of violence capable of attacking not only life but existence as well. Establishing a logic of fantastic terror, the position of victims drops into a void of meaning that breaks what can be felt or said. However, a phenomenologicalhermeneutical approach to the experience of eleven relatives of people disappeared in Colombia casts doubt on the total desire for violence and reveals that the introduction of the non-place does not withhold the relationship with those who are absent. Rather, our results suggest that the missing person may resound, manifest in dreams, or become the fabric for the act of weaving. It is in these spaces of appearance where activism against their absence is articulated.

\section{KEYWORDS: Enforced disappearance, sound, textile practices, dreams, memory.}

\section{R E S U M O}

Na Colômbia, o desaparecimento tem registrado uma violência capaz de atacar não somente a vida, mas também a existência. Instaurando uma lógica de terror fantástico, o lugar das vítimas cai num vazio de sentido que quebra o sensível e o dizível. Contudo, uma aproximação fenomenológicohermenêutica da experiência de 11 familiares de desaparecidos na Colômbia coloca em dúvida o desejo totalizador da violência e revela que a introdução do não lugar não acaba com a relação com os ausentes. Ao contrário, nossos resultados sugerem que o desaparecido possa ecoar, manifestar-se em sonhos ou se tornar tecido no ato de tecer, nesses espaços de aparecimentos em que uma militância é articulada contra a ausência.

PALAVRAS-CHAVE: desaparecimento forçado, som, práticas têxteis, sonhos, memória. 


\section{N T R O D U C C I Ó N}

Tras la Ley de Víctimas 1448 de 2011 y la firma de los acuerdos de paz entre el Estado y la ex-guerrilla de las Fuerzas Armadas Revolucionarias de Colombia - Ejército del Pueblo (FARC-EP), el país enfrenta no solo su cruenta historia de horror, sino la difícil tarea de atender las heridas abiertas provocadas por cincuenta años de guerra. Y aunque son numerosos los vejámenes a los que fueron sometidas las víctimas de la violencia, si de heridas abiertas se trata, la desaparición es tal vez una de las más distintivas y complicadas.

Por definición, la desaparición encarna el problema de dar orden donde no es posible. Mientras el Instituto Nacional de Medicina Legal (2019) registra 29270 personas desaparecidas por el conflicto armado, el Registro Único de Víctimas (RUV) reconoce 42447 casos (UARIV, 2019) y el Observatorio de Memoria y Conflicto -en adelante OMCunos 80407 (Centro Nacional de Memoria Histórica -en adelante CNMH-, 2018). Pero no solo existen problemas para tener cifras precisas, también hay dificultades para caracterizarlas. Por un lado, el OMC registra 38025 desapariciones cuyos autores son aún indeterminados (CNMH, 2018), por otro, el Instituto Nacional de Medicina Legal (2019) señala 116367 casos sin clasificar. No obstante, si bien los problemas de subregistro y tipificación se deben en parte a una deficiente colaboración interinstitucional, hay que reconocer que las cifras y tipificaciones intrínsecamente tienen problemas en tanto tratan con una violencia dirigida, particularmente, a la posibilidad de representación. 
El desaparecido puede entenderse como el producto de lo que Diana Taylor (1997) denomina percepticidio: "Las personas [son] forzadas a concentrarse en lo que fue dado para ser visto y para ignorar las atrocidades dadas para ser invisibles" (p. 119; traducción propia). Su horror reside no en su ataque a la vida, sino en su ataque a la existencia. Se trata del quebrantamiento del sentido (Gatti, 2008), provocado a su vez por un ataque a los sentidos. La falta de precisiones sobre el fenómeno surge, en primer lugar, de la imposibilidad de escuchar, ver o tocar a la víctima. Tratamos así con una violencia planeada y perfeccionada para negarse a sí misma en el despliegue de un acto mágico y perverso, capaz de borrar un fragmento de la realidad sensible con sus actores y circunstancias. No está el desaparecido, no está quien lo desaparece, no hay un mapa para ubicarlo, tampoco razones o motivos que expliquen los hechos.

Ahora, aunque lo anterior supone serias dificultades para un Estado cuyo deber es la búsqueda, supone también serias y profundas dificultades para quienes esperan y añoran al desaparecido -124 427 según el RUV-. La experiencia y los afectos han sido totalizados por una suprarepresentación que, como explica Nancy (2006), roba la muerte de un otro para convertirle en la afirmación de una verdad absoluta: aquí no ha ocurrido nada porque no había nadie en primer lugar. El desaparecido es el cumplimiento de un proyecto estético en el que reina la impoluta verdad que impone el violento. Como resultado, el cariño por un ser querido se fuerza al no-lugar.

Dado lo anterior, no es raro que el percepticidio sea perpetuado institucionalmente por discursos reconciliatorios y narrativas celebratorias. Como señala Estela Schindel (2014), estas construcciones retóricas exponen cierta dificultad de aceptar las pérdidas y admitir el trauma social generado por los contextos de violencia política: "el procesamiento del trauma histórico lleva más tiempo del que las instituciones políticas podrían estar dispuestos a aceptar" (p. 259). En efecto, Carlos Andrés Ramírez (2016) comenta que, en el escenario transicional colombiano, las víctimas deben enfrentarse continuamente a varios procedimientos de neutralización del trauma por medio de la incorporación de su sufrimiento "dentro de alguna narrativa pacificante y totalizadora" (p. 311). Las ciencias psicológicas han tenido un rol importante aquí como encarnación de un "poder pastoral secular" que busca acallar las manifestaciones de aquellos duelos problemáticos para la narrativa reconciliadora oficial (Ramírez, 2016). 
De este modo, en la discusión actual sobre desaparición forzada en Latinoamérica, la figura de los fantasmas cobra cada vez más fuerza como categoría que recorre los intersticios del duelo, el trauma y las políticas de memoria en el marco de las violencias sociales (Gordon, 2008; Meloni, 2019; Schindel, 2014; Tello, 2016). La aparición de las historias fantasmales habla de la posibilidad de narratologías alternativas que, situándose en los límites de los discursos hegemónicos, señalan la insistencia de un pasado problemático que no ha sanado a pesar de los intentos oficiales por "superarlo" (Schindel, 2014). No obstante, Mariana Tello (2016) sugiere que el problema de la espectralidad como tópico para el análisis de los efectos de la desaparición forzada goza de una reputación dudosa en las ciencias sociales, mostrando que lo hegemónicamente establecido como "conocimiento legítimo" tiende a exorcizar lo espectral para darle muerte. Así, el análisis de las presencias fantasmales se constituye como un lugar habitual en el estudio de grupos "alejados de los cánones del pensamiento occidental, [pero] cuando los fantasmas en cuestión remiten a los desaparecidos [...] no se puede dejar de experimentar una cierta incomodidad interpretativa" (Tello, 2016, p. 43).

Abordar lo fantasmal plantea el desafío de "repensar las restricciones que impone una epistemología empirista y una ontología de lo visible y lo concreto equiparado a lo real" (Tello, 2016, p. 43). Nos suscribimos en esta línea de pensamiento al proponer la presente investigación, que busca dar cuenta de las distintas formas en las que los sujetos se reconfiguran ante el dolor de la desaparición forzada en el contexto colombiano. En consecuencia, rastreamos tres maneras en las que entrevemos la manifestación de posibles grietas en al aparataje percepticida: lo sonoro, lo onírico y lo textil. En primer lugar, analizaremos lo sonoro como el lugar en el que se abre la posibilidad del encuentro angustiante y amoroso con el desaparecido en su ominosa presencialidad. Posteriormente, proponemos la dimensión onírica en sus posibilidades éticas como un campo de interpelación entre los vivos y los espectros. Finalmente, se explorará el trabajo textil como práctica reflexiva y nostálgica que tiene la potencialidad de generar puentes comunicativos con la presencia-ausencia.

\section{METODOLOGÍA}

La presente propuesta sugiere un acercamiento fenomenológicohermenéutico a las experiencias de los familiares de personas 
desaparecidas. Particularmente, nos basamos en los supuestos del Análisis Fenomenológico Interpretativo (IPA), que comprende la experiencia humana como un constante proceso de construcción de sentidos desde la relación entre lo sensorial y lo simbólico (Smith y Osborn, 2007). Así, los testimonios de los participantes fueron abordados sin la imposición de categorías previas, indagando por los procesos de significación y su relación con la experiencia sensorial.

Lo anterior requirió -tanto por el tema abordado, como por la metodología- un trabajo concentrado, no en la palabra, sino en aquello que la posibilita y la excede: la acción en el mundo. De esta manera, se optó por un acercamiento a la cotidianidad que, como sugiere Briggs (1986), tuviera como objetivo hacer con los otros. Así, los encuentros y conversaciones se caracterizaron por la posibilidad de escuchar, ver, tocar y tejer con las participantes, a fin de explorar de manera conjunta la memoria y su lugar entre cuerpo y significado.

En detalle, se contó con la participación de diez mujeres y un hombre. Seis son familiares de víctimas de ejecuciones extrajudiciales -más conocidas como "falsos positivos"-, dos son familiares de víctimas de grupos guerrilleros -Ejército de Liberación Nacional (ELN) y Fuerzas Armadas Revolucionarias de Colombia - Ejército del Pueblo (FARC-EP)-, otros dos son familiares de víctimas de agentes aún desconocidos y una es familiar de una víctima de paramilitares. De los once participantes, seis han recuperado el cuerpo de sus seres queridos, mientras cinco aún esperan su retorno. No obstante, atendiendo a Mahlke (2017) y Zorio (2011), entendemos la desaparición no solo como la ausencia del cuerpo, sino como la ausencia del sentido que lo acompaña. De este modo, tanto el vacío narrativo producido por la ausencia repentina, como la falta de verdad y justicia, perpetúan, para todos los participantes, el dilema de que la vida sea ilegible a causa de un no-saber todavía asediante.

Con respecto a las entrevistas, dependiendo de la disponibilidad de tiempo de los familiares -y su deseo de seguir conversando-, se realizaron entre uno y tres encuentros con cada uno, para un total de 18 entrevistas. Se procuró que las conversaciones ocurrieran en espacios seguros y cómodos -en su mayoría, las casas de los participantes-. Finalmente, aunque la mayoría de los participantes solicitó el uso de sus nombres verdaderos -en expresa búsqueda de visibilizar sus casos-, otros pidieron el uso de seudónimos para su identidad y la de sus seres queridos. 


\section{RESULTADOS: MILITANCIAS SENSIBLES CONTRA LA AUSENGIA}

\section{Musicalizar espectros}

Si decimos que la efectividad del percepticidio ha de ser puesta en duda es porque los familiares de los desaparecidos señalan que la ausencia del cuerpo no deriva necesariamente en la ausencia de la presencia. Los testimonios aquí reunidos revelan que el ser querido puede manifestarse a los sentidos a través de materialidades insólitas por-fuera-de-sí. Una de ellas es el sonido.

Frecuentemente, los familiares señalan que a través de la audición se han encontrado con la presencia de sus seres queridos. Sin embargo, dichos encuentros no nacen enteramente de la voluntad consciente de quien escucha. Antes que nada, son enfrentamientos con una presencia que resuena por su propia cuenta. Así lo relatan Lucía ${ }^{1}$ y Sandra ${ }^{2}$. La primera fue visitada en su casa por el anuncio singular de su hijo Javier. La segunda, escuchaba frecuentemente el llamado de su hijo Jaime, quien la nombraba por su apodo en plena calle.

Días antes de que yo me diera cuenta de esa noticia [del asesinato de su hijo], él llegaba y golpeaba [la puerta] así con los cuatro dedos... Un día, eran como las 4:30 de la mañana, estaba lloviendo y la puerta sonó. Yo escuché clarito. Quedé sentada en la cama y dije "llegó Javier". Entonces abrí esta ventanita y le dije "hijo, ya llegó, ya le abro". No lo encontré por ningún lado. No había nada, estaba lloviendo. Al otro día pregunté al vigilante y me dijo: "No, nadie llegó”. (Lucía, en entrevista, 2018)

Yo cruzaba por todos los lugares, me ponía a llorar y me acordaba. Era como tener una película y... ahí lo tenía [...]. Iba caminando y sentía que él me decía “igorda!” y yo volteaba a mirar y no había nadie. (Sandra, en entrevista, 2018)

Los familiares parecen encontrarse con un sonido "autómata", una presencia que les insta, aunque no debería, porque no hay nadie allí. Esto

1 Lucía es madre de Javier, joven desaparecido y asesinado por el ejército colombiano.

2 Sandra es madre de Jaime, joven desaparecido en el Pacífico colombiano por la guerrilla de las FARC-EP. 
podría entenderse bajo lo que Freud (1986) denominó la experiencia de lo siniestro: la aparición de algo familiar-el toque en la puerta, el apodomaterializado de manera extraña. El ser querido y añorado llama, pero se revela luego que el origen de su llamado proviene de un intruso: un no-lugar.

Ahora bien, no es propiamente la ausencia de cuerpo -el modo de aparición- lo que remueve al testigo, es la decepción innombrable que ocurre en el espacio entre lo familiar y lo extraño. En primer lugar, el sonido manifestado "sin más" representa un quiebre en el sentido, particularmente, en la unidad imaginaria del cuerpo donde a cada voz le corresponde una fuente (Gunn, 2004). La resonancia sin resonante no corresponde a la realidad en la que hemos sido formados, más bien, ha sido reprimida y/o delimitada a lo mágico. No obstante, la experiencia se torna siniestra luego, en la sobreposición de esta represión y la representación del objeto amado y familiar. De acuerdo con la teoría lacaniana, si el objeto de deseo es una representación posible de la pérdida original en el plano de lo real-aquello que excede el lenguaje- (Soler, 1993), cuando el sujeto entiende que tal objeto es irrepresentable -una voz sin cuerpo-, se encuentra entonces con lo real y, así, con la pérdida original inabordable. El problema yace en que su deseo ya no tiene lugar, mas no porque su objeto esté ausente, sino porque es en sí inenarrable.

De esta manera, los familiares entrevistados reportan transitar en un mundo de resonancias de una presencia dolorosa e incómoda que les genera terror, evitación y rechazo. Así lo manifiesta Sandra, quien se llenó de odio por los espacios que lucen y suenan como el lugar donde su hijo fue desaparecido, una zona selvática del Pacífico colombiano.

[Era] muy triste porque, como le decía, lo que eran los verdores, los árboles, ;uy!, los odiaba. La lluvia, el viento, yo todo eso lo odiaba, porque allá todos los lugares son tupidos y allá se escuchan todos los ruidos. Allá en la noche se ven esas cositas que prenden y apagan, animalitos que prenden y apagan y se escuchan ruidos: “ipraa!”, “fiuuu!”. (Sandra, en entrevista, 2018)

Sin embargo, como señala Toop (2016), "se pueden cerrar los ojos, pero no los oídos" (p. 15). El problema del espectro es que insiste, y cuando lo hace a través del sonido es inescapable. Al no requerir una fijación en el espacio, el sonido puede tocar, y no solo la piel sino el interior, resonando dentro de quien escucha (Burrows, 1990). En consecuencia, 
aunque Sandra odiara la memoria sonora del desaparecido, nos cuenta que tuvo que aprender a vivir con ella, introduciéndose, por fuerza de la irrepresentabilidad, en una cotidianidad espectral.

Hay una canción que era terrible. Yo no me podía subir a un bus porque siempre sonaba. ¡Uy! Me tocaba bajarme. ¿Sabe qué hice para poder manejar ese dolor y ese llanto -porque yo me ponía a llorar en los buses-? Hice que mi sobrina la grabara en el celular, ese era el sonido del teléfono. (Sandra, en entrevista, 2018)

Una situación similar nos comenta Fernando ${ }^{3}$. A través de la analogía con una ruptura amorosa, nos cuenta que con frecuencia busca las canciones que le recuerdan la relación con su hijo desaparecido como un acto de enfrentamiento al dolor.

Es como el que está bebiendo con "tusa", que pone la canción que dice "ella me traicionó..." y vea y repita y póngala, y se imagina la imagen, de verdad ella con el otro... Eso me pasa con esas canciones. Yo veo a Antonio, en algún momento, en alguna escena. (Fernando, en entrevista, 2018)

Observamos entonces que, tan frecuentemente como la insistencia espectral irrumpe a los entrevistados, ellos también traen los sonidos espectrales de sus seres queridos. La intrusión del sonido puede convertirse en invocación. No obstante, Fernando y Sandra nos plantean una pregunta particular: ¿es la invocación el resultado de una mera habituación a la inevitabilidad del sonido y la memoria? El acto de esfuerzo sugiere lo contrario. Los testimonios hablan de un intento por ejercer la voluntad sobre la disrupción sonora del espectro. Aunque la memoria del desaparecido sea aterradora, en tanto carga algo indecible, incluso esta se puede aprender a escuchar.

La experiencia de los entrevistados no solo se puede leer a través de la disrupción, sino también bajo lo que Boym (2001) llama una relación nostálgica con el pasado. Para la autora, la nostalgia se expresa como un acto renuente a la moderna linealidad del tiempo, donde los sujetos llenan activamente el presente de presencias pasadas. Esto puede manifestarse en dos direcciones, una restaurativa, preocupada por

3 Fernando es padre de Antonio, joven desaparecido en una zona selvática del Guaviare por agentes aún indeterminados. 
reconstruir el pasado, y otra reflexiva, cuyo fin es construir el mundo sobre sus ruinas (Boym, 2001). Ambas formas de nostalgia pueden identificarse en los testimonios. Sandra menciona que suele recordar a su hijo a través de la salsa. Sin embargo, las canciones, en lugar de producir rechazo o incomodidad, pueden dar lugar al goce. Esto, particularmente, se da por la restitución de un lugar de encuentro con quien se añora. Así, durante una celebración de fin de año, mientras Sandra bailaba con su otro hijo una canción de salsa, sentía que se hallaba también en los brazos de Jaime.

Hay mucha música que a mi hijo [Fabio] le gusta porque a Jaime le gustaba y nosotros la bailamos. Entonces, [bailar] me hizo acordar de mi mono, pero no con tristeza, sino con mucha alegría [...]. Bailar con mi otro hijo era como estar en los brazos de los dos. Había momentos donde yo cerraba los ojos y como que me metía en el cuento de los dos. (Sandra, en entrevista, 2018)

En diálogo con el testimonio de Sandra, Alexander Stein (2004) explica que el placer de escuchar música cuando se duele por un ser querido está dado por las capacidades trans-temporales del sonido. Según el autor, el hecho de que este no permanezca atado a un espacio fijo hace que pueda hablar de un momento sin habitarlo. De esta manera, el sonido abre canales de comunicación con el pasado que posibilitan el encuentro entre el añorado y el añorante. Un paso más allá, Nancy (2007) describe el sonido no como un medio para el encuentro, sino como la representación de la relación misma. Es en el sonido donde los sujetos dejan de ser cuerpos separados, para convertirse en una resonancia -y presenciacompenetrada. Su memoria puede borrar al individuo en cuanto individuo y hacer presente una resonancia amada.

Sin embargo, los testimonios señalan que en el ámbito de lo sonoro existe un inevitable paso a la nostalgia reflexiva. Aquí, los familiares no hablan de un encuentro satisfactorio, sino de la memoria sonora como un desencuentro sobre el cual se construye la vida presente. Según Toop (2016) esto se debe a que la transitoriedad del sonido no solo da presencia, sino que la arrebata en "un estremecimiento en el aire, que desaparece de repente" (p. 48). El sonido es la reproducción de la pérdida, o, como señala Iain Foreman (2011), una "amplificación de la ausencia”. Es una dislocación con la experiencia presente que no solo abre un canal al pasado, sino que retiñe su longitud, señalando que la posibilidad de la 
memoria únicamente puede yacer en sus ruinas. $\mathrm{Ana}^{4}$ menciona esta sensación cuando describe la experiencia de escuchar las grabaciones de voz de su hija. Aunque ha decidido últimamente no acudir a estas, nos explica que solía hacerlo para construir un espacio de encuentro. Sin embargo, este siempre resultaba insatisfactorio. De manera similar, Sandra -mientras escuchábamos la canción "A la memoria del muerto" de Fruko y sus tesos- nos habla de cómo esta, aunque le recuerda bailar con Jaime, también le habla de la necesidad de seguir "bailando" la vida a pesar del dolor de no tenerlo.

\begin{abstract}
Porque no la veo, porque la quiero tener, no la tengo y quiero tenerla cerca, más cerca que de costumbre, escuchando su voz. Eso me martiriza, porque [con] su voz es como si la tuviera ahí, pero no la veo, no la veo. La puedo ver ahí, pero no la puedo ver en persona. Eso me hace mucho daño, pero es como si la tuviera. La tengo y no la tengo, ¿cómo lo explico? (Ana, en entrevista, 2018)
\end{abstract}

¿Sí ve? es una canción muy triste, usted la escucha y es muy triste. "Que bailen y que gocen a la memoria del muerto" y "que tomemos mucho traguito”. Pero... ¿qué fue lo que esa persona le dejó? ¿Le dejó tristezas? ¿Le dejó alegrías? Lo que él ha dejado en mí han sido muchas alegrías, que me lo hubieran quitado fue lo que causó dolor. Entonces, es que el mío no está muerto, pero yo soy la viva, entonces hay que seguir bailando el baile, pero el baile de la vida. (Sandra, en entrevista, 2018)

No obstante, aquí se nos pide un cuidado especial. El dolor de Ana -y el de los demás familiares- no proviene precisamente de la distancia con una pérdida. El daño que genera la memoria -sea intrusiva o voluntariaemerge del problema del no saber: es decir, en tanto la ausencia no se puede constatar, el desaparecido siempre es una presencia ambigua. De tal manera, el desencuentro no es la confirmación de la ausencia, es la confirmación del vacío de sentido y su exceso incontrolable.

El desaparecido no es ni una presencia de la que se pueda hacer cuerpo, ni una ausencia condenada a las ruinas, habita entre ambas. Así, traer su memoria no puede aspirar a la dominación de su terror inherente. Más bien, requiere la capacidad de conversar con su carácter indomable

4 Ana es madre de una joven colombiana desaparecida en Quito (Ecuador) por agentes aún indeterminados. 
y asediante, "que siempre registra el daño infligido o la pérdida sostenida por una violencia social" (Gordon, 2008, p. xvi). El trabajo del pasado intrusivo no consiste en su integración o domesticación, sino en "aprender a vivir" con fantasmas en tanto señalan un estado del mundo por atender (Derrida, 2012).

Como consecuencia, la posibilidad de invocación supone un compromiso: escuchar lo que el espectro tiene que decir. En este orden, los familiares entrevistados hablan de hacer una vida no sobre la ausencia, sino sobre el no-saber; ambigüedad que el sonido se encarga de hacer audible. De esto modo, la nostalgia posible en escenarios de desaparición termina por confundirse con la melancolía freudiana. No se busca ni la presencia completa, ni la ausencia presente, más bien, se manifiesta una proliferación de espectros provocados por un fallo en la representación, pero no porque se desconozca qué se perdió, sino porque se desconoce cómo nombrar la pérdida (Agamben, 2006). En esta medida, la invocación no es un acto retroactivo, sino una tensión tendida hacia el futuro; no es acidia, es actividad dirigida a la resolución de un deseo sin lugar (Agamben, 2006).

Sandra, quien desconoce el estado de vida o muerte de su hijo, manifiesta desear que su vida responda a los deseos que Jaime tendría para ella. Aunque su muerte sea una posibilidad, piensa que su presencia debe mantenerse a través de su cuerpo, con el fin de representarlo ante los demás, pero también para alegrarle donde quiera que esté, reconociendo también la posibilidad de su vigencia. Lucía, luego de visitar el lugar donde el cuerpo de su hijo fue abandonado hace 11 años, manifiesta haberse encontrado con un paisaje ambiguo, donde sonidos ausentes y presentes señalan un no-saber que le demandan una acción en el mundo.

Me gusta cuando voy a los ejercicios [de baile]. Me acuerdo de mi monito y digo: "si él supiera que ya no me morî". Porque yo estoy segura de que él, en el momento en que ya lo iban a matar, pensó en mí y dijo: "ella no aguanta". Dizque yo no aguantaba, vea dónde voy, pero por él. A mí me conocen es por él, yo represento a mi hijo, él sigue adelante. (Sandra, en entrevista, 2018)

Yo lo veía en todas partes y me imaginaba "por aquí pasó” [...]. ¡Ay no! yo escuchaba dolor, gemidos, escuchaba gritos mudos, auxilio, "mamá". Los escuchaba ahí. Pero igual, yo digo, si él ahí llegó muerto, ¿el gritar dónde fue? ¿Dónde gritó tanto? ¿Dónde me llamó? Eso es lo que yo 
quiero saber. Ese es otro punto que me queda por investigar. (Lucía, en entrevista, 2018)

El encuentro sonoro con el desaparecido es una experiencia aterradora que trastorna el sentido del mundo y lo convierte en un lugar de resonancias ambiguas y fantásticas. No obstante, su insistencia debe ser aprehendida. El desaparecido pervive y dicta algo que no es fácil de escuchar. Así, "aprender a vivir” en la resonancia de cuerpos y espectros es un trabajo de relacionamiento con el objeto amado al que no se puede ni se debe renunciar. Luego es allí, en las vibraciones etéreas, donde se gestan el amor, la añoranza, la pérdida ambigua, la movilización y la búsqueda.

\section{Transmisiones oníricas}

Las situaciones extremas de violencia provocan en los sujetos acciones inéditas ante lo imprevisible e irrepresentable de sus pérdidas (Da Silva, 2009). Por esto, quebrando el orden "natural del mundo", orden social en el cual los sujetos se relacionan, se mueven, sienten y viven, los individuos se ven abocados a redefinir sus relaciones con los otros y con su propia identidad. En el contexto de la presente investigación, la exigencia de redefinición emanada de la desaparición forzada ha llevado a los familiares de los desaparecidos no solo a reconfigurar su propia experiencia vital y a (re)inventar los modos de relacionamiento con la ausencia-presencia, sino también a explorar nuevas formas sensoriales de habitar el mundo de la pérdida en el incesante flujo entre el sueño y la vigilia.

De este modo, para Mariana Tello (2016), la desaparición forzada presenta una gran eficacia simbólica como herramienta de dominación al arrojar la materialidad de la persona al terreno de lo ilocalizable, ocultando historias y rastros (Colombo, 2013), mientras que, en simultáneo, su presencia persiste en el entorno social del familiar que espera. Esto produciría la insólita emergencia de unas presencias espectrales insidiosas y angustiantes que circulan en la vida cotidiana de los sujetos. Así se ha visto afectada la familia de Beatriz y Vivian ${ }^{5}$, quienes han tenido que convivir con unos espectros que las acechan y asustan.

5 Beatriz es madre de Weimar y tía de Edward, quienes fueron desaparecidos y asesinados en Ciudad Bolívar, Bogotá, en 2004. Tanto Beatriz como Vivían -hermana de Edward y prima de Weimar- han estado vinculadas activamente en la búsqueda de la verdad sobre sus casos. 
Me tocó quitar el cuadro de Edward, porque yo me levantaba y lo primero que veía era ese cuadro. Y él pasaba por ahí caminando. Yo le decía entonces: "no, hermano, no me asuste porque yo le tengo mucho miedo a los fantasmas. No me vaya a asustar, yo a usted lo amo, lo adoro con todo mi corazón, no me vaya a asustar”. (Vivian, en entrevista, 2018)

Mire que... en mi caso, estoy recostada y... “¡ay, alguien pasó por el patio!". A uno le da curiosidad y va y mira y no hay nadie. Mi hijo también se levanta y me dice: "¡ay mami!, yo no quiero dormir allá porque siento que hay alguien, yo sentí que alguien respiró”. (Beatriz, en entrevista, 2018)

Estas mujeres se ven enfrentadas a un haunting, entendido como la ocupación siniestra de su oikos: aquel recinto familiar, de confianza e íntimo donde se mora con tranquilidad (Freud, 1986). Este oikos se verá alterado por la presencia de unos espectros que nacen de la herida del trauma y que señalan el vacío de sentido de una pérdida irrepresentable. El haunting opera aquí como un dispositivo de terror ejercido por la violencia política que se vale del horror para hacer de lo familiar un lugar amenazante (Meloni, 2019).

Sin embargo, la paradoja del espectro radica en que, en su propio núcleo de emergencia como fenómeno de la violencia y del trauma, señala tanto una tecnología del terror como una figura que carga consigo un reclamo de justicia y la posibilidad alternativa de relacionamiento con la pérdida inexpresable (Derrida, 2012; Gordon, 2008; Schindel, 2014). Así las cosas, Carolina Meloni (2019) sugiere que el haunting, como espacio liminar entre dominación y agencia, puede metabolizarse, retorcerse, para resignificarse como la necesidad ética de "aprender a vivir" con los fantasmas: "yo ya no me asusto, no pienso que sea un espíritu malo. Cuando yo de pronto veo o siento que alguien me respira acá... yo digo que es Weimar" (Beatriz, en entrevista, 2018).

La proliferación de los espectros en la vida cotidiana de los familiares entrevistados da cuenta de que el percepticidio dista de implantar un vacío sensorial total y marca el surgimiento, más bien, de una sensibilidad alternativa frente a la inexpresabilidad de la pérdida. Proponemos que una de las formas de torsión del haunting se encuentra en la rearticulación sensorial de los sueños, donde se aguza una sensibilidad etérea, vaporosa y sutil en la búsqueda del lugar de la pérdida ambigua del desaparecido. 
En este orden de ideas, Cathy Caruth (1996) aborda el trauma desde una pregunta fundamental: ¿qué significa sobrevivir? La autora propone que el trauma puede ser entendido como la carga del enigma de la supervivencia: un estado liminar entre la experiencia de la destrucción y el haber sobrevivido a esta, produciendo así un legado de incomprensividad. El trauma representa un quiebre en la experiencia temporal del sujeto al registrar una pérdida que, sin embargo, no puede ser completamente asimilada por el aparataje simbólico del sujeto. Aparecen así los sueños como unas tentativas inacabadas por aprehender la experiencia traumática: "El regreso de la experiencia traumática en el sueño no es la señal de la experiencia directa, sino, más bien, del intento de sobreponerse al hecho de que esta no fue directa, de intentar dominar lo que nunca se aprehendió del todo" (Caruth, 1996, p. 68). En los sueños el sujeto accede a una dimensión en la cual se puede establecer una relación con la pérdida en su exceso e inabordabilidad, intentando con ello trabajar sobre y con la pérdida.

En los casos de desaparición forzada aquí analizados, los sueños aparecen atravesados por unas presencias que ahora tienen la oportunidad de hablar y ser escuchadas. A diferencia de las experiencias diurnas de aparición, en los sueños los fantasmas no emergen de forma disruptiva, no atacan con violencia la sensibilidad del familiar, no desbordan su experiencia sensitiva. El espacio onírico se empieza a configurar como ese sitio "donde los Otros tienen lugar y donde el sujeto debe resolver su acceso al mundo" (Ludueña, 2016 p. 124), de forma tal que, en el contacto con la pérdida, las personas pueden metabolizar el terror del haunting. Si Weimar antes aparecía ante su madre como aquel objeto amado ominoso, en los sueños, al tomarse la palabra, le obsequia a Beatriz un destello de comprensión.

Un día yo estaba acostada, estaba soñando... y Weimar llegó y se sentó. Yo no sabía cómo preguntarle... ¿cómo le pregunto?: “hijo, usted no...”. No, no me atreví a decir nada... porque no sabía si era verdad o si era mentira. Yo le quería preguntar si estaba muerto. No me atreví a preguntarle, pero él me contestó: "sí mami, lo que pasa es que estoy en el cielo, estoy cuidando a unos niños”. ¿Eso qué es?, esos sueños... que se me cruzan entre la realidad... él ya no está, ¿entonces cómo me lo dijo? (Beatriz, en entrevista, 2018) 
De manera similar, Soraida ${ }^{6}$ experimentó múltiples apariciones diurnas. En sus narraciones brota reiteradamente el tema del terror que surge de no poder dar cuenta de las apariciones fantasmales de su hijo. En su caso, el haunting se presentaba de forma tan paralizante que esperó un año y dos meses antes de poder emprender la búsqueda de su familiar porque, después de haber sido asesinado, a Matías "lo veían” en el barrio. No obstante, en los sueños el espectro de su hijo deja de ser una entidad agobiante y terrorífica para rearticularse en la cotidianidad de su familia.

Yo a mi hijo sí lo vi parado agarrado del armario, pero en sueños. ¡Y sí! Yo digo que era él, porque yo tengo en mi cuarto una cortina y eran las dos de la mañana y cuando yo me desperté la cortina hacía así [movimientos ondulados con la mano]. [...] No me dio miedo. Decía: "pero, ¿qué será lo que me quiere decir?, ¿por qué me hace así?, ¿por qué me hace así tres veces?”. Y yo sé que él estuvo ahí, yo ya sé que él en las noches llega... pero no me da miedo. (Soraida, en entrevista, 2018)

Ahora bien, si los sueños son aquel lugar en el cual es posible algún tipo de contacto con la pérdida, ¿qué tipo de relación es la que se establece aquí? En primera medida habría que señalar que, tanto para Cathy Caruth (1996) como para Jean Allouch (2011), la pérdida del objeto instaura un agujero en lo real que señala la imposibilidad de su apropiación por medio de los significantes puestos en juego en el trabajo del duelo. Aunque ciertos elementos del orden simbólico sean convocados para subsanar este agujero, lo que sucede es una simple tentativa.

Por otro lado, Caruth (1996) sugiere un giro en el análisis de los sueños al concebirlos no ya como una función del dormir, sino como una función del despertar. Esto tensiona los supuestos tradicionales según los cuales el sueño cumpliría la función de prolongar el dormir del soñante, así como realizar sus deseos (Freud, 2017). Esto sucede porque no soñamos para dormir; soñamos para despertar: "Es el sueño mismo lo que despierta al durmiente, y es en este despertar paradójico que el soñante confronta la realidad de una muerte de la cual no puede huir" (Caruth, 1996, p. 104). Cuando los fantasmas aparecen en los sueños, el despertar representa un intento de responder a una llamada que únicamente puede ser escuchada en el plano onírico. De esta forma, Lucía nos cuenta que, en

6 Matías, hijo de Soraida, era un vendedor ambulante. Fue desaparecido en Bogotá y asesinado en Norte de Santander en el 2008 por agentes del ejército colombiano. 
un sueño donde se encuentra cerca de una cascada con Javier, acontece la siguiente conversación.

Cuando yo lo vi, me levanté y lo abracé. Nos abrazamos y nos pedimos perdón [...]. Yo le dije que me perdonara si yo había cometido algún error o algo para que él se hubiera ido. Él me pidió perdón por haberse ido y por si me había hecho sufrir. Nos sentamos, él en una piedra y yo en la otra. Hablamos de cómo estábamos, de limpiar mis lágrimas, de la cascada, de que la brisa del agua nos golpeaba la cara y era un frío bonito. (Lucía, en entrevista, 2018)

El contacto que se da en los sueños puede definirse no como un tipo de relación epistemológica con la pérdida -entendiéndola e integrándola como un hecho empírico concreto-, sino como una relación ética con lo real -construyendo un lazo con el espectro sobre la imposibilidad de dar una respuesta apropiada a sus designios- (Caruth, 1996). No obstante, el giro que plantea Caruth, sugiere un flujo constante entre lo onírico y la vigilia, un constante desbordarse el uno en el otro, desmarcando así tales dicotomías y revelando su porosidad o, como nos lo dijo Beatriz (en entrevista, 2018): "los sueños se meten tanto en uno que se introducen en lo que uno piensa y en lo que uno ve. Usted ve muchas cosas, usted piensa tanto en el día que se lo llevan sus sueños y allá vive”. De este modo, el encuentro con la pérdida no puede ser localizado adentro o afuera del sueño, sino que su lugar se encuentra en el desdibujamiento de una esfera en la otra.

El despertar lleva consigo la carga de una transmisión onírica que intenta dar cuenta de lo que significa "escuchar las palabras impensables del muerto" (Caruth, 1996, p. 111). En consecuencia, el familiar recibe las palabras del espectro, pero no las escucha ya como un vivo escucha a un vivo, "sino como aquel que recibe la brecha entre la muerte del otro y su propia vida" (Caruth, 1996, p. 112). De este modo, en el espacio intermedio entre el soñar y el despertar le es legado al sujeto un mandato ético que debe extender en la vigilia: transmitir la alteridad del ausente y sus reclamos. Esta es la inyunción ${ }^{7}$ que Doris ${ }^{8}$ recibe, un legado que subraya la

\footnotetext{
7 Para Derrida (2012), la inyunción es aquella designación que viene dada desde el lugar del espectro, un tipo de mandato o imposición que nos compromete de alguna manera con su presencia-ausencia.

8 Doris es la madre de Óscar, desaparecido en Cúcuta y asesinado en el Copey, Cesar, por las Fuerzas Armadas Colombianas en 2007. Su cuerpo aún no ha sido encontrado.
} 
imposibilidad de comprender la pérdida, pero que no renuncia a su tarea de transmisión.

Yo tuve un sueño el día en que mi hijo estaba allá agonizando. Eran las 10 de la noche. No se me ha olvidado y no se me olvidará nunca. Yo precisamente estaba soñando con él y, como yo lo tuve en mi vientre, él me estaba comunicando lo que estaba sintiendo. Me estaba transmitiendo el dolor que estaba sintiendo. Me lo estaba traspasando. Ya se estaba desconectando la vida de él de la mía. Era una forma de decirme "me estoy yendo". Pero yo no lo entendía, no, yo no lo podía creer, ni lo podía entender. (Doris, en entrevista, 2018)

Se enlazan así las sensibilidades etéreas con las transmisiones oníricas, aquellos susurros que, anudados a unas percepciones espectrales en el flujo de la vida onírica y diurna, piden de los vivos que se narre la historia de la desaparición, tal y como nos lo contó Doris tras narrar el sueño anteriormente citado.

Uno no tiene tranquilidad porque lo deja todo y empieza una búsqueda por saber la verdad, a exigir justicia, a exigir que estas cosas nunca se repitan jamás en la vida. Pero siguen sucediendo, siguen desapareciéndose jóvenes. ¿Por qué?, porque no hay justicia, y cuando no hay justicia seguimos en las mismas. (Doris, en entrevista, 2018

En los casos aquí analizados los sueños se mostraron en el entrecruzamiento de unas experiencias sensoriales concretas y unas transmisiones oníricas que se ponen en juego en el despertar de los familiares de los desaparecidos. Si la proliferación de los espectros hace parte de unos dispositivos de dominación por medio del terror paralizante, los fantasmas se revelan como entidades paradójicas y contradictorias que, al mismo tiempo, tienen la potencialidad del retorcimiento ético del haunting. La potencia de los sueños reside en que logran ser el espacio de articulación de la relación del sí-mismo con los otros espectrales, señalando siempre "una hendidura en lo humano que abre a mundos donde la conciencia es incapaz de penetrar y devela que el pensamiento está permeado por otro-que-sí-mismo" (Ludueña, 2013, p. 67). 


\section{La trama de la ausencia}

En el quebrantamiento del sentido provocado por los actos de desaparición, que generan una violencia directamente en contra de los sentidos -escuchar, tocar, ver-, se pretende borrar un fragmento de la realidad sensible. Sin embargo, como hemos mostrado, los sujetos y las presencias espectrales encuentran fisuras en la realidad por medio de las cuales resisten el percepticidio, creando una forma de relacionamiento y de articulación del sí-mismo con el otro. De esta forma, sostendremos que las materialidades y las prácticas textiles representan un modo de relacionamiento con los otros espectrales. Para ello, en este apartado discutiremos, en primer lugar, en torno a la noción de lo transicional en Donald Winnicott, poniendo en evidencia las características de este fenómeno para el caso de la desaparición forzada. Esto permitirá pensar el carácter reflexivo y nostálgico que encarna el hacer textil en relación con un estado de transitoriedad y habitabilidad de la pérdida.

Para Winnicott (1979), los objetos transicionales permiten la asimilación y agencia sobre la separación dolorosa del bebé y la madre. Así pues, cuando se produce la pérdida de un ser amado inicia un fenómeno transicional por medio del cual se designa la zona intermedia de experiencia entre la realidad del mundo exterior y la ilusión del mundo interno. Winnicott (1979) sostiene que "existe un estado intermedio entre la incapacidad del bebé para reconocer y aceptar la realidad, y su creciente capacidad para ello" (p. 19). De esta forma, "la prueba de realidad" sería aquella que constata la verdadera pérdida del objeto amado. Sin embargo, para el caso de la desaparición, el desaparecido encarna una espectralidad que impide que su figura sea sometida a tal "prueba de realidad" como constatación de que el objeto amado ya no existe, pues la desaparición se retiene como una confusión que no puede resolverse en tanto representa la imposibilidad de la confirmación de la pérdida (Peeren, 2014). Al respecto, Sandra Zorio (2011) agrega que el desaparecido es una especie de fantasma que atormenta a los vivos en tanto que comporta en sí mismo la posibilidad siempre abierta de un regreso. Así, lo único accesible de la pérdida es su presencia como ícono y como rastro, pero no como presencia completa y con lugar tangible en el mundo (Taylor, 1997). Así lo expresa Beatriz en una de las entrevistas, cuando dice: "A pesar de no estar... físicamente... aceptar que ya no están... pero que sí están” (Beatriz, en entrevista, 2018). 
Por consiguiente, el estado intermedio y transitorio no es aquel entre lo ilusorio y lo real, sino que es el estado propio ante una pérdida ambigua. Es así como la constatación de realidad es, de hecho, la constatación de un mundo ilusorio. Lo fantástico y lo real se superponen en la desaparición (Mahlke, 2017). De este modo, el fenómeno transicional, para el caso en cuestión, se trata más bien de habitar el estado intermedio entre la pérdida y el duelo que supone la ausencia-presencia del espectro. Entonces, en ese proceso los familiares le dan un lugar de habitabilidad a la pérdida, asumiendo la renovación del lugar del otro más que su mera eliminación (Gibson, 2004). Al respecto, proponemos que el hacer textil es una forma de habitar y dar orden a esta ausencia-presencia.

Él dejó un gran vacío. Nos volteó la vida, nos la recortó. Eso me taladraba. Tengo que elaborar... no sé qué cosas. Entonces me metí al Costurero de la Memoria: con pedacitos de retazos hago una tela y así elaboro una historia. Podía ser la historia de él, la historia de su vida. (Doris, en entrevista, 2018)

El testimonio de Doris señala que la actividad textil es una forma de dar sentido y de organizar la ausencia; de darle un lugar a la presencia ambigua. El tejido en tanto que es un proceso con un orden claro y unos pasos establecidos (Pajaczkowska, 2015), representa un intento por dar orden a lo intransitable asumiendo que es intransitable. Es decir, no es un estado del que se busca salir, sino uno que se pretende habitar. Así, Blanca ${ }^{9}$ muestra cómo pudo empezar a dar consistencia a la historia de su hija pasando de una dificultad para organizar la ausencia ambigua a un deseo de querer comunicar constantemente los hechos. Allí, no se pretende llevar a cabo un duelo, sino mantener esa ausencia presente en el campo social para poder denunciar la violencia.

Al principio yo no podía contar la historia de ella porque me ponía a llorar, ahora ya no, contar la historia de ella me hace más fuerte: quién era, cómo fue, qué le pasó, dónde está. Entonces yo lo plasmo en las telas, para que más gente pueda ver quién era mi hija [...]. Yo cuento la

9 Blanca es una mujer wayuu cuyo esposo fue asesinado en el 2000 por grupos paramilitares. Posteriormente, su hija Irina, integrante de las juventudes comunistas, fue desaparecida en la Guajira y hallada muerta en el 2001. Desde entonces, Blanca ha sido objeto de diversos actos de intimidación y seguimiento que buscan impedir que exija verdad y justicia para su hija. 
historia de ella porque lo interesante para mí es que el mundo entero sepa lo que pasa en Colombia; que hay impunidad, no hay verdad ni justicia. (Blanca, en entrevista, 2018)

Blanca ha encontrado una forma de habitar la pérdida de su hija asumiendo que su ausencia se convirtió en una forma de compartir (con) su presencia (Bello-Tocancipá y Aranguren, 2020). Al respecto, Gibson (2004) señala que la presencia del otro se transforma, mas no se pierde, habita tanto sensorial como pulsionalmente de una manera distinta, en la que el hacer textil se convierte en un lugar posible para la relación entre la tejedora y su ser querido.

Cuando yo estoy tejiendo, me concentro y pienso en mi hija. Digo: "mija, ayúdame, que todo me vaya bien, hijita, que yo no me enferme casi". (Blanca, en entrevista, 2018)

Cuando yo estoy, como por decir, arrumada y empiezo a tejer, digo: "esto lo estoy haciendo en homenaje a mi hijo". Entonces, cuando yo estoy tejiendo cierro los ojos y me parece verlo cuando se estaba echando el perfume... se daba unas palmadas en el rostro y me decía: “Mami, ¿cierto que soy lindo?”. Y esa es la forma que yo tengo de estar con él: ponerme a tejer y a pensar en él. (Gloria ${ }^{10}$, en entrevista, 2018)

Estos testimonios dan cuenta de una forma de relacionamiento con la presencia-ausencia del ser perdido en la que el hacer textil extiende un puente de comunicación. En términos relacionales, la posibilidad de contar y de ordenar la experiencia posibilita la renovación del lugar del otro, dándole un nuevo espacio de habitabilidad en la cotidianidad. También implica una reconfiguración del lugar en el mundo para sí mismo, pues se debe aprender a vivir con los rastros de la ausencia.

En el proceso de elaboración de un objeto textil, la materialidad se convierte en un lugar depositario de la manifestación de un cuerpo ausente, un rastro metonímico de la presencia del otro (Gibson, 2004). En el hacer se conserva un lugar donde se puede mantener contacto con el objeto amado y donde también se establece una relación con su ausencia.

10 Gloria es madre de Daniel Alexander, un joven detenido y desaparecido extrajudicialmente en el 2008 en Soacha, Bogotá. 
Yo a Óscar le había tejido un saquito amarillo y blanco, el saco era grande, de mangas grandes, porque él desde pequeño fue fortachón, ¡lo más de lindo! Tengo la idea de volverlo a hacer tal cual... es para tenerlo conmigo, para traer a mi hijo. Yo busqué y tengo cuatro pañales de tela de él, quiero bordarlos, son muy significativos [...]. Yo todavía no me he desprendido de él, no lo he dejado ir, porque por medio de estas cosas yo puedo hablar con él cuando sea, puedo verlo, hablarle. Y hasta que su cuerpo no aparezca, yo no lo voy a dejar ir. (Doris, en entrevista, 2018)

De esta forma, el hacer textil se convierte en una manera de reintroducir insistentemente el pasado en el presente. Para Pajaczkowska (2015), tejer es una actividad que se transforma reflexivamente por medio de la necesidad de retroceder con cada puntada para poder avanzar; esto implica una forma de recuperar un origen perdido, es una forma de traer memorias, es "una reflexión activamente pasiva” (p. 86). Esta naturaleza reflexiva del acto repetitivo de tejer y bordar posibilita lo que Boym (2001) llama una relación nostálgica con el pasado que, en este caso, se manifiesta en una dirección reflexiva, cuyo fin no sería propiamente construir un modo de habitar el mundo sobre los rezagos de la pérdida, sino la marca del compromiso que se construye sobre el misterio de una presencia ambigua y de una perdida que se sabe irrepresentable.

En términos psicológicos, el movimiento reflexivo se antepone a la manifestación de los efectos patológicos y traumáticos de la desaparición en los familiares, porque el hacer textil permite trabajar creativamente la ausencia en términos de vivir con esa pérdida presente. El duelo tiene un alcance que es creador e instaurador de una posición subjetiva hasta entonces no concretada: "No se trata de recobrar un objeto o una relación con un objeto [...] se trata de un trastorno en la relación de objeto, de la producción de una nueva figura de la relación de objeto" (Allouch, 2011, p. 205). Así pues, dadas las características de la pérdida, la ausencia siempre es una presencia insidiosa. De este modo, la repetitividad del hacer textil como forma de actuar sobre la pérdida implica, en términos materiales, hacer algo con esta, trabajando así sobre el asedio.

El acto repetitivo tiene como consecuencia que no haya objeto sustitutivo: "ya que por sostenido que sea el esfuerzo por hacer de un nuevo objeto un objeto de sustitución, quedará el hecho mismo de la sustitución como diferencia ineliminable: la segunda vez nunca será la primera" (Allouch, 2011, p. 205). Entonces, el hacer textil se presenta como una tentativa simbólica sensitiva y corporal por dar sentido al agujero creado 
por la pérdida ambigua. En este intento, se pretende coincidir el agujero real de sentido con la fisura simbólica (Allouch, 2011). Como dice Sandra Zorio (2011): "realidad y ficción parecieran jugarse una cruzada" (p. 262).

Si mi Diosito ya se lo llevó de este mundo, yo le pido que lo tenga y que le dé su luz, pero que no lo tenga por allá en la oscuridad. Porque ya son 14 años... entonces yo pienso: "Ay... ¿cómo estará?, ¿estará mojado?, ¿estará sin dormir?, ¿estará sin comer?”. Todo eso. Yo tejo todo con mucho amor, porque si yo te hago una camisa, yo pienso "si abriga, si ella siente el calor, puede mi hijo sentir ese calor". Yo siempre lo pienso. Entonces, si él está mojado, yo pienso que de pronto el calor que tú sientes lo alivia a él. [...] De pronto mi hijo esté con frío y si yo le hago un saco a una niña o a un niño, puede ser que ese niño se lo coloque y ese calor que sienta él al ponérselo, se lo transmita a mi hijo que podría tener frío. (María ${ }^{11}$, en entrevista, 2018)

Sin embargo, estas tentativas de hacer coincidir la brecha real con la fisura simbólica son siempre inéditas, pues ¿cómo reconciliar el hecho de que el desaparecido es un muerto-vivo que acecha desde la muerte, pero que a la vez es un ser vivo que podría estar pasando fuertes necesidades fuera de casa? ¿Cómo cobijar del frío a un cuerpo que no está pero que hay que abrigar? El intento es siempre resbaladizo.

Ahora bien, durante la elaboración de una pieza textil, como las telas bordadas de Doris, los sacos tejidos de María o los bordados de Blanca, hay un tiempo y una energía invertidos en la manufactura de cada pieza. Así, la energía corporal y afectiva empleada en el trabajo textil se canaliza por medio del proceso de catexia hacia el objeto. Según Gibson (2004), catexia es el término para señalar la descarga emocional y pulsional investida sobre un objeto. Sin embargo, en el caso de la creación textil manual ya no solo se carga al objeto con energía pulsional, sino que, por medio de la fuerza corporal y emocional implicada en el trabajo, este queda cargado también con el aura del ser querido, lo que lo convierte en un lugar material de habitación para el espectro que se transforma, a su vez, en un emisario de su propia historia. Por ejemplo, Blanca, hace tejidos que incorporan en sus hebras la esencia de su hija y se los regala a otras personas para que la lleven consigo.

11 María es la madre de un soldado de la fuerza pública que fue secuestrado por el ELN en el 2007. María no sabe qué pasó con él y le pide a la justicia que le diga el estado de vida o muerte de su hijo. 
Blanca: la esencia de mi hija siempre está en las telas. Yo les he regalado tejidos a algunas de mis amigas, que se los han llevado para otros países. Entonces, yo le digo a mi hija: "yo lo hice para ti, para que te lleven en espíritu esas personas a esos lugares".

Entrevistadora: ¿Es para ella porque ella está presente por medio del objeto?

Blanca: Claro, jasí ella se mantiene viva! (Blanca, en entrevista, 2018)

Aunque los objetos textiles son lugares de habitación para el sujeto amado, también son el lugar depositario de su pérdida (Gibson, 2004). La relación con el objeto textil es una relación con un rastro, y aquel rastro no es sino una huella que atestigua la presencia de algo que ya ha escapado del espacio y de la propia sensibilidad. De este modo, los objetos textiles se encargan de conservar un lugar donde se pueda mantener contacto con el objeto amado y donde también, a su vez, se establezca una relación con su ausencia-presencia.

Por otro lado, en cuanto a la agencia de emisión de la propia historia, los textiles narrativos que cuentan historias de violencia y de dolor de manera explícita -como es el caso de las telas de Mampuján (Parra, 2014) - narran por sí mismos la historia que ha sido puesta sobre estos: "La persona escribe de forma textil su historia, su denuncia y sus dolores sobre la tela, y esta -como una cómplice- se encarga de contarlo, liberando a la persona de la carga de repetirlo una y otra vez; ahora tiene una compañera que cuenta también" (Bello, 2018, p. 75). Esto tiene como consecuencia la circulación en el ámbito social, no solo de las historias de violencia sino también del espectro. Es el espectro circulando entre hilos y telas.

Como consecuencia, la labor artesanal textil plantea la posibilidad de dar un lugar relacional a la ausencia a la vez que se pone a circular la presencia, tanto en el ámbito privado como en el ámbito social. Así, como la trama de un tejido que va y viene por la urdimbre, el espectro juega entre la realidad y la ilusión siendo visto en unos momentos e intuido en otros, pero, en todo caso, siendo una ausencia siempre presente. 


\section{CONCLUSIÓN}

Hemos sugerido que la desaparición supone un intento por invisibilizar la existencia, no solo a modo de ocultamiento o asesinato de la vida, sino también como forma de ocultar la experiencia sensorial del relacionamiento con los otros. El desaparecido es escindido de su lugar de existencia en el mundo, por lo cual los familiares son arrojados a un vacío de sentido en el que no hay una pérdida confirmada pero tampoco una existencia visible. Por lo anterior, hemos propuesto que los familiares han desarrollado modos de resistir la violencia en contra de los sentidos articulando un modo de relacionamiento ético-político con la presencia. Este relacionamiento no pretende integrar la pérdida ni mucho menos domesticarla; busca, en cambio, aprender a vivir con la dicotomía existencial inherente al desaparecido, creando formas sensoriales inéditas de relacionarse con este. Así pues, encontramos que la experiencia sonora es el medio por el cual se puede ser hallado por el espectro. La experiencia onírica, por su parte, establece una correspondencia ética con lo real articulando la relación de sí mismo con los otros espectrales por medio del flujo entre sueño y vigilia. Por último, las prácticas y objetos textiles tienen la posibilidad de dar cuerpo a un cuerpo ausente materializando la posibilidad de sentir, y dando lugar a la no-materialidad de su presencia por medio de materiales que abrigan y abrazan la presencia de la ausencia.

\section{REFERENCIAS}

Agamben, G. (2006). Estancias: La palabra y el fantasma en la cultura occidental. Pretextos.

Allouch, J. (2011). Erótica del duelo en tiempos de la muerte seca. El cuenco de plata.

Bello, A. C. (2018). Cuando las palabras faltan, las manos hablan: Construcciones de sentido en torno a las prácticas textiles en el conflicto armado colombiano [tesis de grado]. Universidad de los Andes.

Bello-Tocancipá, A. y Aranguren, J. P. (2020). Voces de hilo y aguja: Construcciones de sentido y gestión emocional por medio de prácticas textiles en el conflicto armado colombiano. H-ART. Revista de historia, teoría y crítica de arte, 6, 181-204. https://doi.org/10.25025/hart06.2020.10

Briggs, C. (1986). Learning How to Ask: A Sociolinguistic Appraisal of the Role of the Interview in Social Science Research. Cambridge University Press. https://doi. org/10.1017/CBO9781139165990

Boym, S. (2001). The Future of Nostalgia. Basic Books.

Burrows, D. (1990). Sound, Speech and Music. Massachusetts University Press. 
Caruth, C. (1996). Unclaimed Experience. Trauma, Narrative, and History. The Johns Hopkins University Press.

CNMH. (2018). Observatorio de Memoria y Conflicto. http:// centrodememoriahistorica.gov.co/observatorio/infografias/

Colombo, P. (2013). Del traslado de detenidos-desaparecidos o el espacio en movimiento: Hacia una fenomenología de la percepción distorsionada. CEIC, $4(20), 1-28$.

Da Silva, L. (2009). No habrá flores en la tumba del pasado: La experiencia de reconstrucción del mundo de los familiares de desaparecidos. Ediciones Al Margen.

Derrida, J. (2012). Espectros de Marx. Editorial Trotta. https://doi. org/10.4324/9780203821619

Foreman, I. (2011). Uncanny Soundscapes: Towards an inoperative acoustic community. Organized Sound, 16(3), 264-271. https://doi.org/10.1017/ S1355771811000276

Freud, S. (1986). Lo ominoso. En J. Stratchey (Ed.), Obras completas (Vol. XVII, pp. 215-51). Amorrortu editores.

Freud, S. (2017). La interpretación de los sueños. En S. Freud, Obras completas (Tomo 1, pp. 343-713). Biblioteca Nueva.

Gatti, G. (2008). El detenido desaparecido: Narrativas posibles para una catástrofe de la identidad. Trilce.

Gibson, M. (2004). Melancholy objects. Mortality, 9(4), 285-299. https://doi.org/10. 1080/13576270412331329812

Gordon, A. (2008). Ghostly Matters. Minneapolis: University of Minnesota Press.

Gunn, J. (2004). Mourning speech: Haunting and the spectral voices of nine-eleven. Text and Performance Quarterly, 24(2), 91-114. https://doi. org/10.1080/1046293042000288344

Instituto Nacional de Medicina Legal. (2019). Consultas públicas, desaparecidos y cadáveres. http://190.26.211.139:8080/consultasPublicas/

Ludueña, F. (2013). H. P. Lovecraft. La dis-yunción en el Ser. Hecho Atómico Ediciones.

Ludueña, F. (2016). Principios de espectrología. Miño y Dávila.

Mahlke, K. (2017). Figuraciones fantásticas de la Desaparición Forzada. En G. Gatti, Desapariciones. Usos locales, circulaciones globales (pp. 75-98). Siglo del Hombre Editores; Universidad de los Andes.

Meloni, C. (2019). Cadáveres insumisos: Hacia una ética del asedio y de la hospitalidad. Papeles del CEIC, 1, 1-21. https://doi.org/10.1387/pceic.19512

Nancy, J. (2006). La representación prohibida. Amorrortu.

Nancy, J. (2007). A la Escucha. Amorrortu.

Pajaczkowska, C. (2015). Making Known, the Textiles Toolbox-Psychoanalysis of Nine Types of Textile Thinking. En J. Jefferies, W. Conroy, D. Hazel y C. Hazel (Eds.), The Handbook of Textile Culture (pp. 79-94). Bloomsbury.

Parra, L. A. (2014). Entre puntadas, palabras y duelos, las 'Tejedoras de sueños' en Mampuján aportan a la construcción de paz [tesis de especialización]. Universidad Nacional de Colombia. 
Peeren, E. (2014). The Spectral Metaphor. Living Ghosts and the Agency of Invisibility. Palgrave Macmillan.

Ramírez, C. A. (2016). Reconciliación como ideología o la verdad del resentimiento. En A. Fjeld, C. Manrique, D. Paredes y L. Quintana, Intervenciones filosóficas en medio del conflicto: Debates sobre la construcción de paz en Colombia hoy (pp. 309-327). Ediciones Uniandes.

Schindel, E. (2014). Ghosts and compañeros: Haunting stories and the quest for justice around Argentina’s former terror sites. Rethinking History, 18(2), 244264. https://doi.org/10.1080/13642529.2013.858452

Smith, J. y Osborn, M. (2007). Interpretative phenomenological analysis. En J. Smith (Ed.), Qualitative psychology: A practical guide to research methods. Sage.

Soler, C. (1993). El cuerpo en la enseñanza de Jacques Lacan. Estudios de Psicosomática, 1, 1-7.

Stein, A. (2004). Music, Mourning, and Consolation. Journal of the American Psychoanalytic Association, 52(3), 783-811. https://doi.org/10.1177/0003065104 0520031801

Taylor, D. (1997). Disappearing acts: spectacles of gender and nationalism in Argentina's "Dirty War". Duke University Press. https://doi.org/10.2307/j.ctv11smxf9

Tello, M. (2016). Historias de (des)aparecidos. Un abordaje antropológico sobre los fantasmas en torno a los lugares donde se ejerció la represión política. Estudios en Antropología Social, 1, 33-49.

Toop, D. (2016). Resonancia siniestra: el oyente como médium. Caja negra.

UARIV. (2019). Registro único de víctimas. https://www.unidadvictimas.gov.co/es/ registro-unico-de-victimas-ruv/37394

Winnicott, D. (1979). Realidad y juego. Gedisa editorial.

Zorio, S. (2011). El dolor por un muerto-vivo. Una lectura freudiana del duelo en los casos de desaparición forzada. Desde el Jardín de Freud, 11, 251-266. 